\title{
Journal of Respiratory Research
}

\section{Focusing on Donor Lung Organ Storage: Implications for Inflammation Post-Transplant}

\author{
Wolfgang Jungraithmayr, Vaibhav Gupta, Rebecca Orndorffand Shampa Chatterjee
}

\begin{abstract}
Wolfgang Jungraithmayr, MD, Division of Thoracic Surgery, University Hospital Zurich, Zurich, Switzerland

Vaibhav Gupta, Institute for Environmental Medicine, University of Pennsylvania School of Medicine, Philadelphia, PA, USA

Rebecca Orndorff, PhD, Institute for Environmental Medicine, University of Pennsylvania School of Medicine, Philadelphia, PA, USA

Shampa Chatterjee, PhD, Department of Physiology, University of Pennsylvania School of Medicine, Philadelphia, PA, USA
\end{abstract}

Conflict-of-interest statement: The author(s) declare(s) that there is no conflict of interest regarding the publication of this paper.

Correspondence to: Shampa Chatterjee, PhD, Department of Physiology, University of Pennsylvania School of Medicine, Philadelphia, PA, USA.

Email: shampac@mail.med.upenn.edu

Telephone: +1-215-898-9101

Fax: +1-215-898-0868

Received: August 11, 2016

Revised: September 30, 2016

Accepted: October 7, 2016

Published online: December 28, 2016

\section{ABSTRACT}

Lung transplantation is a surgical option to replace a diseased lung with a healthy lung from a donor. This surgical process causes stop of blood flow from the point of organ retrieval or procurement followed by cold and warm storage phase (ischemia), followed by the reinstatement of blood flow with implantation (reperfusion) that occurs upon transplant. The injury incurred during ischemia (retrieval and storage) together with the injury from reperfusion ( $I / R$ injury) is considered as the main driver of onset of primary graft dysfunction (PGD). PGD is a multifactorial injury that is characterized by cellular infiltrates and severe oxidative damage; it occurs within $24 \mathrm{~h}$ posttransplant and is a critical factor in determining transplant outcome. PGD occurs in large part due to inflammation post-transplant when polymorphonuclear neutrophils (PMN) are recruited to and adhere to the endothelium of the lung, transmigrate and release reactive oxygen species (ROS). Recognizing the role of PMN in poor transplant outcome, the clinical strategy at present is to block PMN activation by a non-specific immunosuppression regimen administered to the transplant recipient. As immunosuppression therapy has severe side effects, alternate means of blocking and inhibiting inflammation in the lung are being considered. The binding of PMN to the endothelium is a prerequisite of inflammation; thus our research is focused on the endothelium of the donor lung so as to block endothelial signals that facilitate its binding to PMN. Such a strategy of inhibiting the moieties on the vascular wall so that as prevent donor lung endothelial interaction with the recipient's PMN is an early intervention and has the potential to prevent injury completely. In contrast, immunosuppression involves minimizing influx and recruitment of PMN and immune cells after the initial adherence and binding that would take place immediately upon transplant. Our extensive work on lung storage or ischemia shows that the pulmonary endothelium responds to stop of blood flow by a signaling cascade that involves KatP channel closure, PI3Kinase activation and assembly of the enzyme NADPH oxidase 2 (NOX2) leading to the generation of ROS. We found that the ROS thus produced triggers the onset of an inflammation cascade during the storage period itself, ahead of the transplant event. Onset of inflammation causes damage to the donor lung during storage thus affecting donor lung availability; additionally it can potentially drive immune cell recruitment via inflamed lung vessel wall. Thus optimal storage conditions such as keeping the lung (organ) perfused or inhibiting ischemia induced signaling by blocking KATP closure, PI3K activation or NOX2 assembly may potentially preserve lung viability and minimize inflammation and injury post-transplant.

Key words: Lung transplantation; Ischemia-reperfusion; Lung storage; Primary graft dysfunction (PGD); Reactive oxygen species; NADPH oxidase 2; KATP channel

(C) 2016 The Author(s). Published by ACT Publishing Group Ltd. This is an open access article under the CC BY-NC-ND license (http: //creativecommons.org/licenses/by-nc-nd/4.0/). 
Jungraithmayr W, Gupta V, Chatterjee ROS. Focusing on Donor Lung Organ Storage: Implications for Inflammation Post-Transplant. Journal of Respiratory Research 2016; 2(3): 79-84 Available from: URL: http: //www.ghrnet.org/index.php/jrr/article/view/1864

\section{INTRODUCTION}

Lung transplantation, the last option for patients with end stage lung diseases consists of a surgical event to replace a diseased and dysfunctional lung with a healthy donor lung and involves an episode of warm and cold ischemia or stop of blood flow (associated with lung retrieval and storage) and reperfusion or reinstatement of blood flow (transplant). The major challenge with lung transplant is ischemia-reperfusion ( $\mathrm{I} / \mathrm{R})$ injury, also known as primary graft dysfunction (PGD) $)^{[1-3]}$. PGD develops within the first $24 \mathrm{~h}$ after transplant and is associated with chronic rejection also known as bronchiolitis obliterans syndrome (BOS) which continues to be the main reason for transplant failure ${ }^{[4-6]}$. Thus, minimizing of I/R injury is a critical factor in alleviating onset of BOS and eventual rejection and loss of the organ.

The hallmark of $\mathrm{I} / \mathrm{R}$ injury or PGD is the onset of inflammation that occurs when polymorphonuclear neutrophils (PMN) from the recipient's circulation are recruited and adhere to the transplanted (donor) lung ${ }^{[2,7-9]}$. Although PMN recruitment is the first line of host defense, excessive adherence and infiltration of PMN into tissue causes tissue damage via the release of reactive oxygen species or ROS by PMN. Studies on animal models have shown that disrupting PMN infiltration and adherence can reduce lung injury after transplant ${ }^{[10,11]}$. Recognizing the role of PMN in I/R injury, the clinical strategy has been to block PMN activation using a nonspecific immunosuppression regimen administered to the transplant recipient ${ }^{[12,13]}$. But this has severe side effects besides being only partially effective.

An alternate strategy would be to target the endothelial cells on the lung vascular wall as the endothelium-PMN binding is a prerequisite to PMN infiltration into inflamed tissues ${ }^{[14,15]}$. Thus "treating" the endothelium so as to reduce or block PMN adherence can potentially shift the therapy from the transplant recipient to the donor lung (graft).

Our past research on the lung endothelium showed that with stop of blood flow, the endothelium lining the vessel wall "senses" loss of flow; this "sensing" initiates a signaling cascade, that causes membrane depolarization via the closure of a KATP channel ${ }^{[16,17]}$. Depolarization causes the activation of membrane potential sensitive domains of Phosphatidylinositol-4,5-bisphosphate 3-kinase (PI3K) that in turn leads to the assembly of all the subunits (the cytosolic subunits p40phox, p47phox, p67phox, Rac and the membrane subunits gp91phox and p22phox) leading to the reduction of molecular oxygen into superoxide anion $\left(\mathrm{O}_{2}^{-} \text {.) (Figure } 1\right)^{[18]}$. Superoxide dismutates to produce hydrogen peroxide $\left(\mathrm{H}_{2} \mathrm{O}_{2}\right)$; all these moieties produced are collectively termed as ROS. ROS is a term that encompasses various free radicals, ions and reactive species that are generated by enzymatic and non-enzymatic sources in various cell types. The ROS produced with lung storage or ischemia activates an inflammation cascade that besides damaging the stored lungs could potentially affect the graft post-transplant ${ }^{[19]}$. Thus blocking ischemia induced signaling in the donor lung would increase viability of lungs during storage and would by minimizing inflammation signals reduce the influx of PMN from the recipient post-transplant. Overall, it would shift the focus from the recipient's immune system to the donor lung's vasculature.

In addition to inflammation induced damage, another major challenge with transplant is allograft rejection that occurs when $\mathrm{T}$ lymphocytes from the recipient recognize non-self forms of class I and class II major histocompatibility complex (MHC) molecules on the cells of the graft. The MHC class I and II expressed on antigen presenting cells (APC) facilitate the presentation of "donor" antigens to T-lymphocytes. The APC-T lymphocyte interaction leads to T-lymphocyte activation, production of cytokines and cell death. The resultant injury also plays a role in onset of rejection ${ }^{[20]}$.

This article will review the signaling associated with lung storage that leads the onset of inflammation during storage ahead of transplant. The overarching theme will be to understand the role of ischemia induced downstream signaling events that are the main drivers of inflammation, injury and graft rejection.

\section{LUNG ISCHEMIA AND REACTIVE OXYGEN SPECIES (ROS)}

Stop of blood flow to any organ results in two changes 1) hypoxia or anoxia as oxygen levels are compromised and 2) loss of shear arising from removal of the mechanical component of blood flow. The lung is an exception to this because lung tissue does not rely on

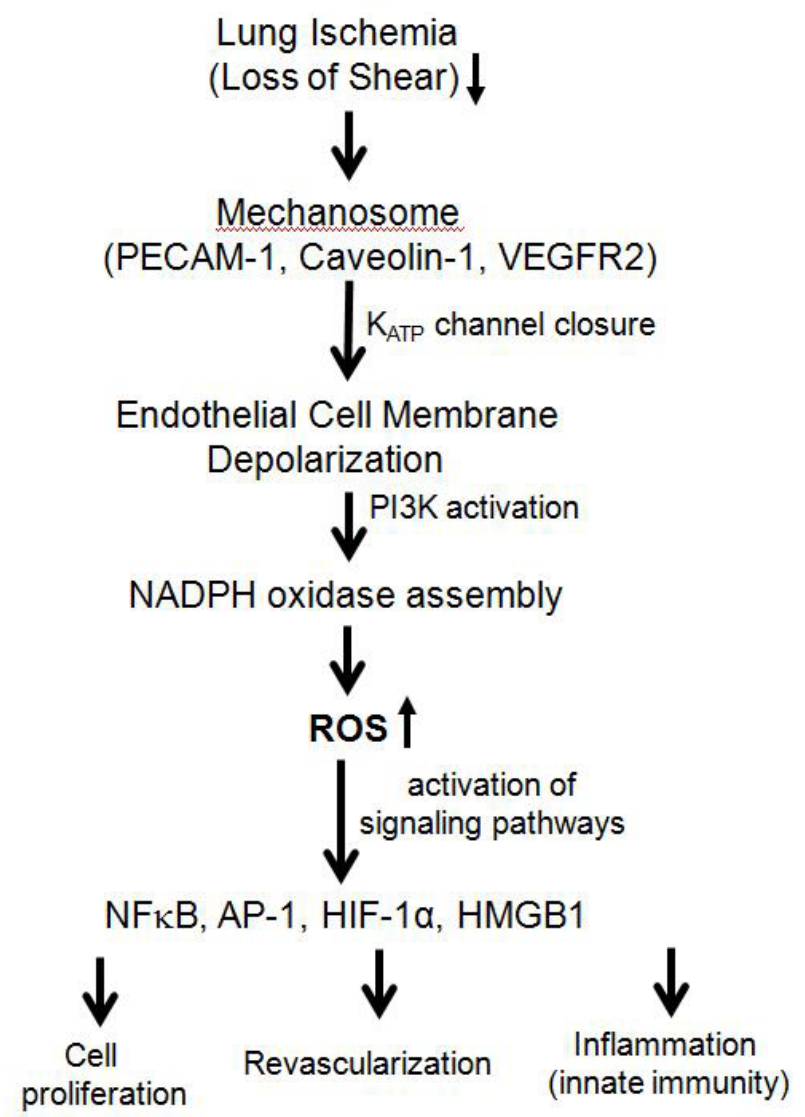

Figure 1 Pulmonary Ischemia induced signaling for reactive oxygen species (ROS) production lung storage. In the lung (unlike systemic organs), ischemia compromises the mechanical stimulus associated with stop of blood flow. Our investigations revealed that loss of shear caused "shear sensing" by the mechanosome comprised of several moieties including caveolin-1, PECAM and VEGFR2. "Shear sensing" led to endothelial membrane depolarization (via a KATP channel induced closure) that causes activation of PI3Kinase. PI3K drives assembly of Rac and other cytosolic NOX subunits thus producing superoxide and $\mathrm{H}_{2} \mathrm{O}_{2}$ (collectively called ROS). The ROS thus produced has been observed to facilitate cell proliferation (in an in vitro model of ischemia), revascularization (in an in vivo model of ischemia) and inflammation (in anin situ donor lung model of ischemia). 
blood flow for its cellular oxygen requirements. Alveolar ventilation or inflation can maintain normal alveolar $\mathrm{pO}_{2}$ and keeps the lung cells oxygenated for a reasonably long period of time. Thus stop of blood flow in the pulmonary system represents the "loss of shear stress" alone ${ }^{[18,21]}$. In the context of lung storage, it is therefore important to understand "loss of shear" induced signaling to enable its inhibition. Loss of shear also occurs in systemic organs with stop of flow but is overshadowed by hypoxia or anoxia induced signaling. Various degrees of hypoxia and thus hypoxia-induced signaling and subsequent damage cannot be avoided in systemic organs with storage; however, in the lung, hypoxia can be limited or avoided altogether by keeping lungs inflated or ventilated. Thus knowledge of "loss of flow" induced signaling and activation of downstream events can assist in reducing the detrimental effects, if any, of lung storage.

We reported earlier that with loss of flow, the pulmonary endothelium in situ and endothelial cells in vitro(in flow chambers that mimic blood vessels) are activated via a KATP channel-NADPH oxidase 2 signaling pathway that causes the production of ROS (Figure 1$)^{[18,21]}$. ROS production was evaluated from oxidation of various ROS-sensitive fluorescence dyes [dihydroethidine (DHE) for superoxide anion, dichlorofluorescein (DCF) for $\mathrm{H}_{2} \mathrm{O}_{2}$, and Amplex red (for intravascular $\mathrm{H}_{2} \mathrm{O}_{2}$ ) $]^{[16,19,21]}$.

ROS production that follows the ischemia signaling cascade that as we reported earlier, involves the "sensing" of the loss of flow stimulus by a complex machinery (for which we coined the term mechanosome) comprising of several elements namely caveolae and platelet endothelial cell adhesion molecule -1 (PECAM-1) ${ }^{[21]}$ along with presumably other moieties like vascular endothelial growth factor receptor 2 (VEGFR-2) as reported by others ${ }^{[2]}$.

The ROS thus produced would cause direct oxidative damage as we observed ${ }^{[14,19,23]}$ but our subsequent investigations revealed that it also triggered various signaling cascades that facilitated endothelial cell proliferation, revascularization, inflammation and the activation of immunomodulatory moieties ${ }^{[14,23-26]}$.

\section{ROS MEDIATED SIGNALING AND DOWNSTREAM EFFECTORS}

\section{Transcription Factors}

The major downstream effects of ROS-mediated signaling are the activation of various transcription factors. In an in vitro model of ischemia, "flow adapted" or "conditioned" endothelial cells that were subjected to stop of flow showed activation of NF- $\kappa \mathrm{B}$ by electrophoretic mobility shift assay as reflected by increased nuclear content ofp65 and p50 subunits; concurrent activation of activator protein 1 (AP-1) was detected by Western blot analysis showing an increase in both c-Jun and c-Fos subunits ${ }^{[27]}$. Activation of these transcription factors was abolished by pretreatment of cells with inhibitors of ROS generation, indicating that their activation indeed is linked to $\operatorname{ROS}^{[28,29]}$. We also observed that a ROS dependent regulation of HIF-1 $\alpha$ expression in a model of stopped flow in vivo ${ }^{[26]}$.

There are many additional transcription factors such as Nrf2and ATF/CREB, that are redox sensitive and might be modulated be ROS that are generated during lung storage or ischemia. The activation of HIF- $1 \alpha$ by ROS that we observed could presumably be mediated by $\mathrm{NF}-\mathrm{KB}^{[30]}$. These redox activated transcription factors are reportedly the trigger for onset of inflammation.

\section{Inflammation}

Inflammation is a complex process regulated by numerous proinflammatory mediators such as cellular adhesion molecules (CAMs) and danger signals of sterile injury such as damage associated molecular patterns (DAMPs) and their receptors (pattern recognition receptors or PRRs). The major CAMs found on the surface of endothelial cells in injured tissue are the intercellular adhesion molecule (ICAM or CD54) and the vascular endothelial cell adhesion molecule (VCAM or CD106) ${ }^{[31,32]}$. We observed that the expression of CAMs that facilitate PMN-endothelial cell binding, are ischemiaROS regulated (Figure 2) ${ }^{[19,25]}$. Besides CAMs, there is hypoxiainducible factor $1 \alpha(\mathrm{HIF}-1 \alpha)$, which transcriptionally regulates a host of inflammatory cytokines ${ }^{[33]}$. HIF- $1 \alpha$ is also known to act through its downstream effector, vascular endothelial growth factor-A (VEGF-A), to facilitate influx and transmigration of neutrophils and other immune cells (e.g. macrophages, mast cells) from the recipient's circulation post-transplant ${ }^{[34,35]}$. ROS produced with ischemia regulates both HIF- $1 \alpha$ and VEGF and may account for revascularization in the vasculature ${ }^{[19,26]}$ or onset of inflammation in situ as observed in human donor lungs ${ }^{[19]}$.

Increase in the DAMP protein high-mobility group box 1 (HMGB1) and increased expression of its PRR, receptor for advanced glycation end products (RAGE), are critical in onset and amplification of inflammation and have been implicated in numerous inflammation pathologies including $\mathrm{I} / \mathrm{R}$ and endotoxemia ${ }^{[36,37]}$. Our earlier work showed that lung storage led to increased induction of both HMGB1 and RAGE ${ }^{[19]}$. HMGB1-RAGE axis is part of a coordinated response that cells use to trigger inflammatory cascades by driving assembly of Nod-like Receptor Protein 3 (NLRP3) inflammasomes ${ }^{[38]}$. NLRP3 inflammasome assembly activates caspase- 1 and mediates the release of the cytokine interleukin, 1-beta (IL-1 $\beta$ ) that causes cell death by pyroptosis (inflammation programmed cell death) ${ }^{[39,40]}$.

\section{Immune Response}

Besides onset of inflammation, ROS is well established to transform endothelial cells into antigen presenting cells (APC). The accepted paradigm is with post-transplant rejection that "professional" APCs such as dendritic cells (DC) present antigens to activate the recipient's naïve $\mathrm{T}$ lymphocytes. The $\mathrm{T}$ lymphocytes thus activated cause production of inflammatory cytokines and other enzymes that cause cytolysis, injury and onset of graft rejection ${ }^{[20,41]}$. However other cells can also behave as APCs; indeed ROS can cause increase in major and minor histocompatibility complex I and II (MHC class I and II) or human leukocyte antigens (HLA-) and co-stimulatory molecules (CD-40, LFA-3 etc.) on endothelial cells and thus drive endothelial transformation into $\mathrm{APCs}^{[41]}$. As endothelial cell-T lymphocyte interaction is pivotal in onset of rejection signaling, blocking ROS in lungs can potentially minimize rejection ${ }^{[20]}$.

We thus conclude that blocking ischemia-induced signaling cascade would be a potential strategy to maintain lung viability during storage ${ }^{[14]}$. Besides the production of ROS and oxidative damage, ischemia itself triggers onset of inflammation. Inflammatory mediators and signals emanating from the donor lungs prime or predispose these lungs for robust inflammation after transplant.

\section{New Strategies and Emerging Therapies for Lung Preservation} Perfusion of donor lungs is now being increasing employed to "rescue" donor lungs that have been found to be unsuitable for transplant (due to high pulmonary vascular resistance and vascular leak). This technique is called ex vivo lung perfusion (EVLP) and involves perfusing and ventilating donor lungs in a closed ex vivo circuit just prior to transplant ${ }^{[42-45]}$. The lungs are perfused at a constant pressure $(20 \mathrm{mmHg})$ with a buffered extracellular normothermic solution at an optimal colloid osmotic pressure (Steen solution, 
Jungraithmayr W et al. signaling with lung transplant

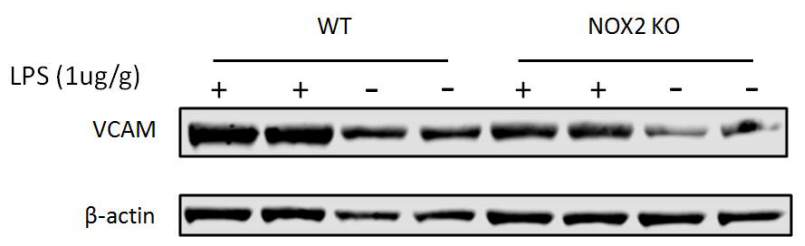

Figure 2 A

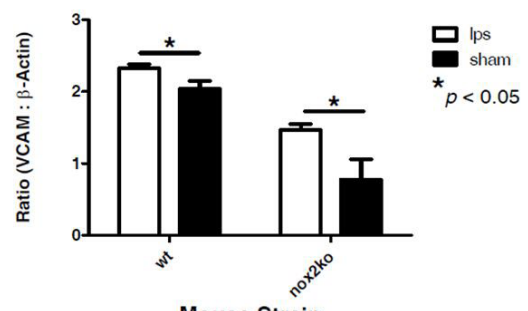

Figure 2 B

Mouse Strain
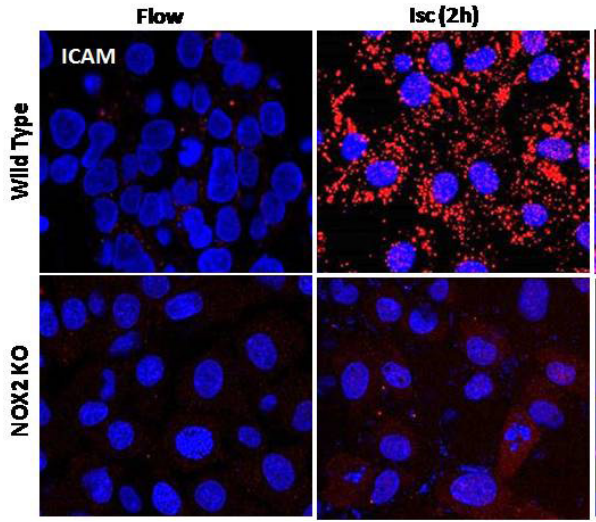

$\operatorname{Rep}(\mathbf{2}$ h)
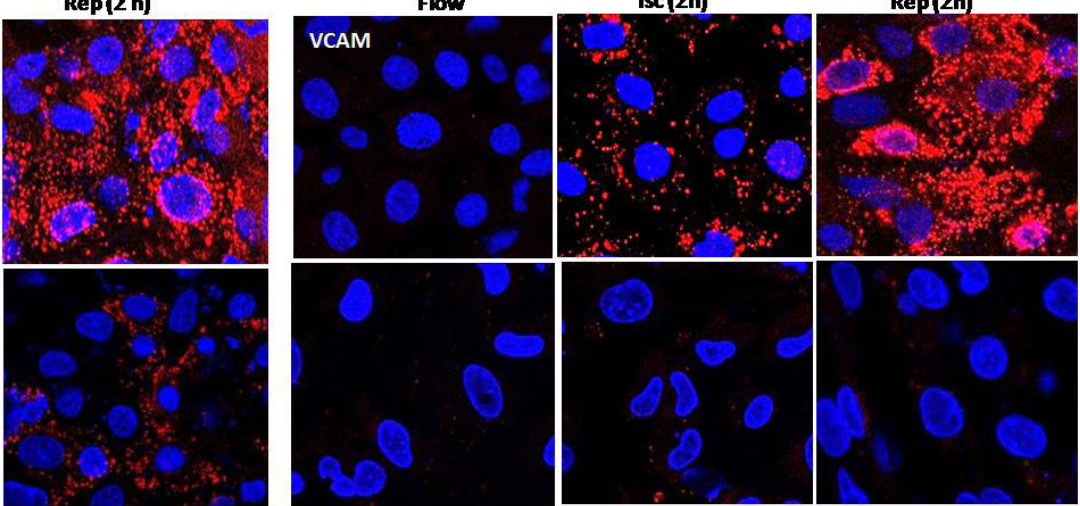

Figure 2 CAM expression is ROS dependent in a model of endotoxin induced inflammation (A) and in a model of ischemia (B). A) VCAM with inflammation as assessed by immunoblotting of lung lysate $24 \mathrm{~h}$ after inflammation has induced by injecting LPS intratracheally into wild type and NADPH oxidase 2 (NOX2) null or KO mice. These mice do not have gp91phox subunit on the membrane and thus cells from these mice do not produce ROS after an inflammatory stimulus. B) ICAM and VCAM as detected by immunofluorescence of cells subjected to ischemia and then to reperfusion in vitro ${ }^{[19]}$. Cells are conditioned to flow (flow adaptation for $24 \mathrm{~h}$ ) followed by stop of flow and re-instatement of flow.

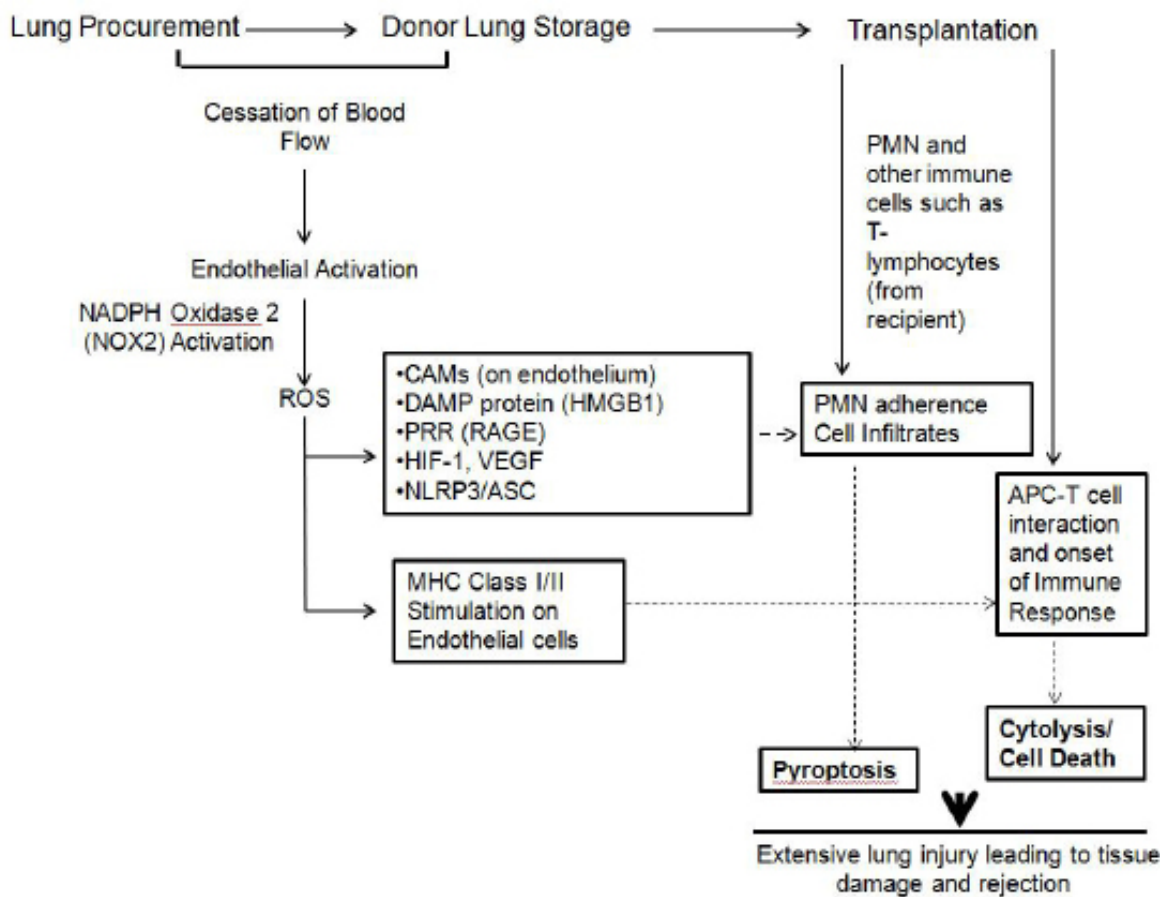

Figure 3 Schema showing lung storage induced ROS as the driving force for inflammation and for immune response during storage and post-transplant. ROS induces the onset of an inflammation cascade (CAMs, HMGB1, RAGE, HIF1- $a$, VEGF) during storage. These predispose the graft to bind to PMN and other immune cells that influx into it after transplant. ROS also drives the transformation of lung endothelium as an antigen presenting cell (APC). As an APC, the endothelium can "present" donor antigens to the T-lymphocytes from the recipient that come into the graft after transplant. The APC-T cell interaction leads to cytokine release and cytolysis. The cumulative damage from these events causes injury and onset of rejection. Bold lines indicate observations based on work carried out in our lab. Dotted arrows are conclusions from studies carried out elsewhere. 
Vitrolife, Sweden). Although EVLP lungs experience a period of storage or ischemia prior to perfusion, yet the perfusion-ventilation approach has shown several advantages (1) prevention of damage before implantation; (2) preservation of the graft over long time interval after harvesting; and (3) repair of potential grafts that may otherwise not have been considered for transplantation ${ }^{[46]}$. We take this concept a step further and propose a "perfusion-ventilation" maneuver from procurement till implantation into recipient. In other words, we suggest that maintaining close to physiological conditions during the procurement and storage periods to minimize ROS and NO production. Studies with animal lungs indicate that a relatively low perfusate flow rate can prevent activation of the "loss of shear stress" signaling cascade. A pilot study carried out using a portable perfusion system (integrated and portable Organ Care System or OCS) showed that normothermic perfusion $\left(34^{\circ} \mathrm{C}\right.$ at a flow rate of $2.5 \mathrm{~L} / \mathrm{min}$ ) of the donor lung from procurement till implantation had a good transplantation outcome (in terms of a 30 day survival period) in a high-risk recipient population ${ }^{[4]}$. Since this was a small cohort (12 lungs) more extensive studies need to be performed over large groups to determine the optimal storage times and perfusion rates that minimize ROS production in human lungs.

Another alternate approach would be to store lungs in buffer supplemented with inhibitors of the "loss of shear" signaling cascade, i.e. inhibitors that prevent the mechanosome activation (anti-PECAM-1 antibodies, sequestering caveolae ${ }^{[21]}$ or prevent depolarization via $\mathrm{K}_{\text {ATP }}$ channel (KATP agonist cromakalim), or inhibit PI3K activation (wortmanin) ${ }^{[18]}$ or prevent NADPH oxidase 2 assembly (MJ33) $)^{[48]}$.

\section{CONCLUSION AND FUTURE DIRECTIONS}

Based our work on lung ischemia (using murine, porcine and human lungs) it is clear that storage conditions are an important factor in the inflammation status of a donor lung; we thus propose that signaling initiated during the ischemia event has the potential to be amplified later (Figure 3), with the caveat that other factors, including those of the recipient, can play a role in determining the final outcome. Till date, studies correlating storage times and lung transplant outcome have been inconsistent. This indicates that the inflammatory signals in the donor lung may or may not translate into clinical symptoms of PGD because recipient factors such as antioxidant status or other risk factors are pivotal in determining outcome. Besides, inconsistency in the definition of PGD may also account for the contrasting conclusions (from clinical trials). Nevertheless, in a broader sense, prevention of ischemia either by maintaining physiological conditions of flow and ventilation or by blocking or inhibiting ROS production is critical in preserve lung viability during storage.

\section{REFERENCES}

1. Christie JD, Bavaria JE, Palevsky HI, Litzky L, Blumenthal NP, Kaiser LR, Kotloff RM. Primary graft failure following lung transplantation. Chest. 1998; 114: 51-60

2. Granton J. Update of early respiratory failure in the lung transplant recipient. Current opinion in critical care. 2006; 12: 19-24

3. King RC, Binns OA, Rodriguez F, Kanithanon RC, Daniel TM, Spotnitz WD, Tribble CG, Kron IL. Reperfusion injury significantly impacts clinical outcome after pulmonary transplantation. The Annals of thoracic surgery. 2000; 69: 16811685

4. Behr J, Maier K, Braun B, Schwaiblmair M, Vogelmeier C. Evidence for oxidative stress in bronchiolitis obliterans syndrome after lung and heart-lung transplantation. The munich lung transplant group. Transplantation. 2000; 69: 1856-1860

5. Madill J, Aghdassi E, Arendt B, Hartman-Craven B, Gutierrez C, Chow CW, Allard J, University Health N. Lung transplantation: Does oxidative stress contribute to the development of bronchiolitis obliterans syndrome? Transplantation reviews. 2009; 23: $103-110$

6. Rahman I, MacNee W. Oxidative stress and regulation of glutathione in lung inflammation. Eur Respir J. 2000; 16: 534-554

7. Fiser SM, Kron IL, Long SM, Kaza AK, Kern JA, Cassada DC, Jones DR, Robbins MC, Tribble CG. Influence of graft ischemic time on outcomes following lung transplantation. The Journal of heart and lung transplantation: the official publication of the International Society for Heart Transplantation. 2001; 20: 12911296

8. Fiser SM, Tribble CG, Long SM, Kaza AK, Kern JA, Jones DR, Robbins MK, Kron IL. Ischemia-reperfusion injury after lung transplantation increases risk of late bronchiolitis obliterans syndrome. Annals of Thoracic Surgery. 2002; 73: 1041-1047; discussion 1047-1048

9. Laubach VE, Kron IL. Pulmonary inflammation after lung transplantation. Surgery. 2009; 146: 1-4

10. Ross DJ, Moudgil A, Bagga A, Toyoda M, Marchevsky AM, Kass RM, Jordan SC. Lung allograft dysfunction correlates with gamma-interferon gene expression in bronchoalveolar lavage. $J$ Heart Lung Transplant. 1999; 18: 627-636

11. Kreisel D, Sugimoto S, Tietjens J, Zhu J, Yamamoto S, Krupnick AS, Carmody RJ, Gelman AE. Bcl3 prevents acute inflammatory lung injury in mice by restraining emergency granulopoiesis. $J$ Clin Invest. 2011; 121: 265-276

12. Hemmert C, Ohana M, Jeung MY, Labani A, Dhar A, Kessler R, Roy C. Imaging of lung transplant complications. Diagn Interv Imaging. 2014; 95: 399-409

13. Camirand G. New perspectives in transplantation through intravital microscopy imaging. Curr Opin Organ Transplant. 2013; 18: 6-12

14. Chatterjee S, Nieman GF, Christie JD, Fisher AB. Shear stressrelated mechanosignaling with lung ischemia: Lessons from basic research can inform lung transplantation. Am J Physiol Lung Cell Mol Physiol. 2014; 307: L668-680

15. Kozower BD, Christofidou-Solomidou M, Sweitzer TD, Muro S, Buerk DG, Solomides CC, Albelda SM, Patterson GA, Muzykantov VR. Immunotargeting of catalase to the pulmonary endothelium alleviates oxidative stress and reduces acute lung transplantation injury. Nature Biotechnology. 2003; 21: 392-398

16. Chatterjee S, Levitan I, Wei Z, Fisher AB. Katp channels are an important component of the shear-sensing mechanism in the pulmonary microvasculature. Microcirculation. 2006; 13: 633-644

17. Chatterjee S, Al-Mehdi AB, Levitan I, Stevens T, Fisher AB. Shear stress increases expression of a katp channel in rat and bovine pulmonary vascular endothelial cells. Am J Physiol Cell Physiol. 2003; 285: C959-967

18. Chatterjee C, Browning E, Hong N, Debolt KM, Sorokina EM, Liu W, Birmbaum MJ, Fisher AB. Membrane depolarization is the trigger for p13kinase/akt activation and leads to the generation of reactive oxygen species Am J Physiol Heart Circ Physiol. 2012

19. Tao JQ, Sorokina EM, Vazquez Medina JP, Mishra MK, Yamada Y, Satalin J, Nieman GF, Nellen JR, Beduhn B, Cantu E, Habashi NM, Jungraithmayr W, Christie JD, Chatterjee S. Onset of inflammation with ischemia: Implications for donor lung preservation and transplant survival. Am J Transplant. 2016

20. Ingulli E. Mechanism of cellular rejection in transplantation. Pediatr Nephrol. 2010; 25: 61-74

21. Noel J, Wang H, Hong N, Tao JQ, Yu KJ, Sorokina EM, Debolt KM, Heayn M, Rizzo V, Delisser HM, Fisher AB, Chatterjee S. Pecam-1 and caveolae form the mechanosensing complex necessary for nox 2 activation and angiogenic signaling with stopped flow in pulmonary endothelium. Am J Physiol Lung Cell 
Mol Physiol. 2014

22. Tzima E, Irani-Tehrani M, Kiosses WB, Dejana E, Schultz DA, Engelhardt B, Cao G, DeLisser H, Schwartz MA. A mechanosensory complex that mediates the endothelial cell response to fluid shear stress. Nature. 2005; 437: 426-431

23. Chatterjee S, Fisher AB. Mechanotransduction in the endothelium: Role of membrane proteins and reactive oxygen species in sensing, transduction, and transmission of the signal with altered blood flow. Antioxidants \& redox signaling. 2014; 20: 899-913

24. Chatterjee S, Fisher AB. Mechanotransduction: Forces, sensors, and redox signaling. Antioxid Redox Signal. 2014; 20: 868-871

25. Orndorff RL, Hong N, Yu K, Feinstein SI, Zern BJ, Fisher AB, Muzykantov VR, Chatterjee S. Nox2 in lung inflammation: Quantum dot based in situ imaging of nox2-mediated expression of vascular cell adhesion molecule-1. Am J Physiol Lung Cell Mol Physiol. 2014; 306: L260-268

26. Browning E, Wang H, Hong N, Yu K, Buerk DG, DeBolt K, Gonder D, Sorokina EM, Patel P, De Leon DD, Feinstein SI, Fisher AB, Chatterjee S. Mechanotransduction drives post ischemic revascularization through $\mathrm{k}$ (atp) channel closure and production of reactive oxygen species. Antioxid Redox Signal. 2014; 20: $872-886$

27. Fisher AB, Al-Mehdi AB, Manevich Y. Shear stress and endothelial cell activation. Crit Care Med. 2002; 30: S192-197

28. Wei Z, Costa K, Al-Mehdi AB, Dodia C, Muzykantov V, Fisher AB. Simulated ischemia in flow-adapted endothelial cells leads to generation of reactive oxygen species and cell signaling. Circ Res. 1999; 85: 682-689

29. Fisher AB, A1-Mehdi AB, Manevich Y. Shear stress and endothelial cell activation. Crit Care Med. 2002; 30: S192-197

30. Bonello S, Zahringer C, BelAiba RS, Djordjevic T, Hess J, Michiels C, Kietzmann T, Gorlach A. Reactive oxygen species activate the hif-1alpha promoter via a functional nfkappab site. Arterioscler Thromb Vasc Biol. 2007; 27: 755-761

31. Granger DN, Kubes P. The microcirculation and inflammation: Modulation of leukocyte-endothelial cell adhesion. J Leukoc Biol. 1994; 55: 662-675

32. Jordan JE, Zhao ZQ, Vinten-Johansen J. The role of neutrophils in myocardial ischemia-reperfusion injury. Cardiovascular research. 1999; 43: 860-878

33. Jeong HJ, Chung HS, Lee BR, Kim SJ, Yoo SJ, Hong SH, Kim HM. Expression of proinflammatory cytokines via hif-1alpha and nf-kappab activation on desferrioxamine-stimulated hmc-1 cells. Biochemical \& Biophysical Research Communications. 2003; 306: $805-811$

34. Marasco SF, Sheeran FL, Chaudhuri K, Vale M, Bailey M, Pepe S. Molecular markers of programmed cell death in donor hearts before transplantation. J Heart Lung Transplant. 2014; 33: 185193

35. Scaldaferri F, Vetrano S, Sans M, Arena V, Straface G, Stigliano E, Repici A, Sturm A, Malesci A, Panes J, Yla-Herttuala S, Fiocchi C, Danese S. Vegf-a links angiogenesis and inflammation in inflammatory bowel disease pathogenesis. Gastroenterology.
2009; 136: 585-595 e585

36. Lamkanfi M, Sarkar A, Vande Walle L, Vitari AC, Amer AO, Wewers MD, Tracey KJ, Kanneganti TD, Dixit VM. Inflammasome-dependent release of the alarmin hmgb1 in endotoxemia. Journal of Immunology. 2010; 185: 4385-4392

37. Kokkola R, Andersson A, Mullins G, Ostberg T, Treutiger CJ, Arnold B, Nawroth P, Andersson U, Harris RA, Harris HE. Rage is the major receptor for the proinflammatory activity of hmgb1 in rodent macrophages. Scand J Immunol. 2005; 61: 1-9

38. Horvath GL, Schrum JE, De Nardo CM, Latz E. Intracellular sensing of microbes and danger signals by the inflammasomes. Immunol Rev. 2011; 243: 119-135

39. Henao-Mejia J, Elinav E, Strowig T, Flavell RA. Inflammasomes: Far beyond inflammation. Nat Immunol. 2012; 13: 321-324

40. Lamkanfi M, Dixit VM. Mechanisms and functions of inflammasomes. Cell. 2014; 157: 1013-1022

41. Abrahimi P, Qin L, Chang WG, Bothwell AL, Tellides G, Saltzman WM, Pober JS. Blocking mhe class ii on human endothelium mitigates acute rejection. JCI Insight. 2016; 1

42. Cypel M, Rubacha M, Yeung J, Hirayama S, Torbicki K, Madonik M, Fischer S, Hwang D, Pierre A, Waddell TK, de Perrot M, Liu $\mathrm{M}$, Keshavjee S. Normothermic ex vivo perfusion prevents lung injury compared to extended cold preservation for transplantation. Am J Transplant. 2009; 9: 2262-2269

43. Cypel M, Yeung JC, Hirayama S, Rubacha M, Fischer S, Anraku M, Sato M, Harwood S, Pierre A, Waddell TK, de Perrot M, Liu M, Keshavjee S. Technique for prolonged normothermic ex vivo lung perfusion. J Heart Lung Transplant. 2008; 27: 1319-1325

44. Cypel M, Keshavjee S. Strategies for safe donor expansion: Donor management, donations after cardiac death, ex-vivo lung perfusion. Curr Opin Organ Transplant. 2013; 18: 513-517

45. Cypel M, Yeung JC, Liu M, Anraku M, Chen F, Karolak W, Sato M, Laratta J, Azad S, Madonik M, Chow CW, Chaparro C, Hutcheon M, Singer LG, Slutsky AS, Yasufuku K, de Perrot M, Pierre AF, Waddell TK, Keshavjee S. Normothermic ex vivo lung perfusion in clinical lung transplantation. $N$ Engl J Med. 2011; 364: 14311440

46. Steen S, Ingemansson R, Eriksson L, Pierre L, Algotsson L, Wierup P, Liao Q, Eyjolfsson A, Gustafsson R, Sjoberg T. First human transplantation of a nonacceptable donor lung after reconditioning ex vivo. Ann Thorac Surg. 2007; 83: 2191-2194

47. Warnecke G, Moradiellos J, Tudorache I, Kuhn C, Avsar M, Wiegmann B, Sommer W, Ius F, Kunze C, Gottlieb J, Varela A, Haverich A. Normothermic perfusion of donor lungs for preservation and assessment with the organ care system lung before bilateral transplantation: A pilot study of 12 patients. Lancet. 2012; 380: 1851-1858

48. Intae Lee CD, Shampa Chatterjee, Sheldon I Feinstein, and Aron B. Fisher. Protection against lps-induced acute lung injury by a mechanism based inhibitor of nadph-oxidase (type 2). American Journal of Physiology: Lung Cell Molecule Physiology. 2014: Accepted

\section{Peer reviewers:}

